\title{
$N$-Methyl-isobutyl-amiloride Ameliorates Brain Injury When Commenced Before Hypoxia Ischemia in Neonatal Mice
}

\author{
GILES S. KENDALL, NICOLA J. ROBERTSON, OSUKE IWATA, DONALD PEEBLES, AND GENNADIJ RAIVICH \\ Centre for Perinatal Brain Protection and Repair, Department of Obstetrics and Gynaecology, University College London, \\ UK WC1E $6 H X$
}

\begin{abstract}
Under physiologic conditions, brain intracellular $\mathrm{pH}$ $\left(\mathrm{pH}_{\mathrm{i}}\right)$ is maintained at 7.03. Rebound brain intracellular alkalosis has been observed in experimental models and adult stroke after hypoxia/ ischemia (HI). In term infants with neonatal encephalopathy (NE), an association exists between the magnitude of brain alkalosis and neurodevelopmental outcome, and there is increasing evidence to suggest that alkalosis may be deleterious to cell survival. Activation of the $\mathrm{Na}^{+} / \mathrm{H}^{+}$exchanger (NHE) is thought to be responsible for the rapid normalization of $\mathrm{pH}_{\mathrm{i}}$ and rebound alkalosis after reperfusion. We hypothesized that $N$-methyl-isobutyl-amiloride (MIA), an inhibitor of the NHE, would reduce brain injury in a model of neonatal HI. Seven-day-old mice underwent left carotid artery occlusion followed by exposure to $8 \%$ oxygen for $30 \mathrm{~min}$ (moderate insult) or $1 \mathrm{~h}$ (severe insult). Animals received MIA or saline 8 hourly starting $30 \mathrm{~min}$ before HI. Outcome was determined at $48 \mathrm{~h}$ by measuring viable tissue in the injured hemisphere (severe insult) or injury score and TUNEL staining (moderate insult). After the severe insult, MIA had a significant neuroprotective effect increasing forebrain tissue survival from $44 \%$ to $67 \%$. After the moderate insult, damage was localized to the hippocampus where treatment resulted in a significant reduction in injury score and in TUNEL-positive cells. MIA was also shown to have a significant overall neuroprotective effect based on injury score after the moderate insult. Amiloride analogues are neuroprotective when commenced before $\mathrm{HI}$ in a mouse model.
\end{abstract} (Pediatr Res 59: 227-231, 2006)

$\mathrm{P}_{\mathrm{i}}^{\mathrm{e}}$ erinatal HI affects approximately one to two per 1000 term infants per year in the United Kingdom and leads to death or severe impairment in more than 750 infants annually (1) Over the past $20 \mathrm{y}$, studies using phosphorus $\left({ }^{31} \mathrm{P}\right)$ and $\left({ }^{1} \mathrm{H}\right)$ proton magnetic resonance spectroscopy (MRS) in both infants with NE (2-4) and experimental models $(5,6)$ have characterized the biphasic disruption of cerebral energetics that occurs in the hours after HI. These observations have led to the concept of a "therapeutic window" after HI, during which intervention may ameliorate the severity of brain injury. Recent results from the first randomized trials of mild hypothermia in term infants with NE are promising (7-9); however, considerable work is still required to optimize cooling strate-

Received May 26, 2005; accepted September 21, 2005

Correspondence: Nicola J. Robertson, F.R.C.P.C.H., Ph.D., Centre for Perinatal Brain Protection and Repair, Department of Obstetrics and Gynaecology, University College London, 86-96 Chenies Mews, London WC1E 6HX, UK; e-mail: n.robertson@ucl.ac.uk

Giles Kendall is an Action Medical Research Training Fellow. This work is also funded by grant support from SPARKS.

DOI: $10.1203 / 01 . p d r .0000196805 .68082 .22$ gies in the newborn. Furthermore, there is a growing impression that optimum neuroprotection may involve the use of more than one therapy, targeting different parts of the neurotoxic cascade.

Under physiologic conditions, brain $\mathrm{pH}_{\mathrm{i}}$ is maintained at approximately 7.03; the NHE tightly regulates both $\mathrm{pH}_{\mathrm{i}}$ and cell volume by extruding protons from and taking sodium up into cells (10). A remarkable observation from the studies employing ${ }^{31} \mathrm{P}$ MRS in infants with NE was that during the secondary phase of energy decline occurring from 8 to $24 \mathrm{~h}$ after birth, brain $\mathrm{pH}_{\mathrm{i}}$ was not acidic but alkaline $\left(\mathrm{pH}_{\mathrm{i}}\right.$ 7.1-7.4) (11). Some evidence suggests that excessive activation of the NHE after HI is responsible for the observed brain intracellular alkalosis (12). Brain intracellular alkalosis has also been observed in experimental models of adult stroke (13) in which longer periods of ischemia were associated with earlier and more prolonged periods of alkalosis (14).

Adult clinical studies have demonstrated brain intracellular alkalosis in areas of chronic infarction after stroke $(15,16)$ with a significant correlation between brain alkalosis and subsequent poor clinical outcome (17). We have recently observed a similar relationship between brain intracellular alkalosis and the severity of brain injury in term infants with $\mathrm{NE}$ (18). Infants with the most alkaline brain $\mathrm{pH}_{\mathrm{i}}$ had more severe changes on magnetic resonance imaging within the first $2 \mathrm{wk}$ after birth and the worst neurodevelopmental outcome at $1 \mathrm{y}$. Interestingly, this brain intracellular alkalosis was seen to persist for some months in those with the worst outcome (19).

These observations led to the hypothesis that blockade of the NHE reduces the severity of brain injury observed after perinatal HI. To establish a proof of concept, we studied whether pretreatment with amiloride, a drug known to block the action of the NHE, is neuroprotective if administered before an HI insult. We chose MIA because this amiloride analogue crosses the blood-brain barrier (20), and we studied the effect of this drug on both moderate and severe HI insults.

Abbreviations: $\mathbf{p H}_{\mathbf{i}}$, intracellular $\mathrm{pH}$; MIA; $N$-methyl-isobutyl-amiloride; HI, hypoxia/ischemia; NHE, $\mathrm{Na}^{+} / \mathrm{H}^{+}$exchanger; NE, neonatal encephalopathy 


\section{MATERIALS AND METHODS}

Surgery. The animal experiments and care protocols were approved by the Home Office and were carried out according to the UK Animals (Scientific Procedures) Act of 1986. Experiments were performed at postnatal day 7 (P7) on the offspring of adult C57/B16 female (Charles River, UK) and males (Harlan UK) bred inhouse. P7 mice were anesthetized with isoflurane (5\% induction, $1.5 \%$ maintenance). The left carotid artery was ligated using an 8-0 polypropylene suture. After a 2 -h recovery with their dam, animals were placed in a warmed chamber $\left(36^{\circ} \mathrm{C}\right)$ and exposed to warmed, humidified $8 \%$ oxygen in $92 \%$ nitrogen for $30 \mathrm{~min}$ (moderate insult) or $1 \mathrm{~h}$ (severe insult).

Ten milligrams MIA (Sigma Chemical Co.) was dissolved in $150 \mu \mathrm{L} 350$ $\mathrm{mmol} / \mathrm{L}$ acetic acid and then diluted to $40 \mathrm{~mL}$ in $0.9 \%$ saline to give a final concentration of $250 \mu \mathrm{g} / \mathrm{mL}$. Aliquots were stored at $-80^{\circ} \mathrm{C}$ until required. Animals were sequentially allocated to receive intraperitoneal injections of MIA $2.5 \mathrm{mg} / \mathrm{kg}(10 \mu \mathrm{L} / \mathrm{g})$ or an equivalent volume of $0.9 \%$ saline every $8 \mathrm{~h}$, starting $30 \mathrm{~min}$ before hypoxia.

Tissue preparation. Animals were killed $48 \mathrm{~h}$ after $\mathrm{HI}$ by intraperitoneal injection of pentobarbitone and perfused with $30 \mathrm{~mL}$ of PBS. The brains were then removed, postfixed for $1 \mathrm{~h}$ by rotating $(8 \mathrm{rpm})$ immersion in $4 \%$ formaldehyde in PBS at $4^{\circ} \mathrm{C}$ as described previously (21) and then cryoprotected for $24 \mathrm{~h}$ in a phosphate-buffered $30 \%$ sucrose solution. Fixed cryoprotected brains were frozen on dry ice, cut on a cryostat into sequential $40-\mu \mathrm{m}$ sections, and stored at $-80^{\circ} \mathrm{C}$ until required. Fifteen sections from each forebrain (200 $\mu \mathrm{m}$ apart) were stained with cresyl violet. In the mild insult group, five coronal sections per brain $(600 \mu \mathrm{m}$ apart) were stained using immunohistochemistry for the microglial and macrophage activation marker using the rat monoclonal 5C6 $\alpha \mathrm{M} \beta 2$ antibody (Serotec) as described previously (21). Five further coronal sections per brain, with the same spacing, were stained using Terminal transferase mediated d-UTP nick end labeling (TUNEL) (Roche). After 15 min of pretreatment with $3 \%$ hydrogen peroxide in methanol to block endogenous peroxidase, sections were stained as described previously (22).

Brain volumes. The cresyl-stained sections were scanned and imported into Optimas image analysis software. The areas of intact staining in the cortex, hippocampus, striatum, and thalamus were outlined and measured bilaterally. Surviving brain tissue was calculated by converting the measured left (injured) and right (uninjured) areas into square millimeters and then converting to a volume by multiplying by $200 \mu \mathrm{m}$. The sum of these volumes was then used to calculate the percentage of surviving brain tissue as left/right volume $\times 100$

Injury score. To analyze the brain injury in tissue without a measurable infarct, an injury score was devised using the cresyl-stained sections and immunohistochemistry for 5C6 $\alpha \mathrm{M} \beta 2$ expression, which can be used to assess microglial activation in areas of tissue damage (23). Scores (Table 1) were then allocated for each brain region (cortex, hippocampus, thalamus, striatum) by an observer blinded to the treatment of the individual animal. The two scores were then added together to give a total $0-7$ point injury score.

Cell death. To quantify cell death involving DNA fragmentation the number of TUNEL-positive nuclei were counted in each brain region. The sections were also scanned into a computer and the area in which the cells were counted was measured. The results were expressed as number of TUNEL positive cells per square millimeter.

Statistics. Statistical significance was assessed using the Student $t$ test unless otherwise stated.

\section{RESULTS}

Severe insult. Twenty animals underwent the severe insult protocol. Four animals died during the hypoxia (two MIA, two

Table 1. Brain injury scoring

\begin{tabular}{cl}
\hline Score & Nissl (cresyl violet) staining \\
0 & No damage \\
1 & Minimal evidence of damage without evidence of infarct \\
2 & Small infarct, $<50 \%$ of the affected region \\
3 & Large infarct, $>50 \%$ of the affected region \\
4 & Total neuronal loss \\
Score & $5 \mathrm{C} 6(\alpha \mathrm{M} \beta 2$ integrin) expression \\
0 & No activation \\
1 & Focal activation \\
2 & Mild diffuse activation, occasional phagocytic macrophages \\
3 & Widespread activation, predominant phagocytic macrophages \\
\hline
\end{tabular}

saline). Four animals died in the subsequent $48 \mathrm{~h}$ (one MIA, three saline). Animals were weighed every $8 \mathrm{~h}$ until they were killed. There was no significant difference in weight between the two groups at the onset of treatment with $4.43 \pm 0.30 \mathrm{~g}$ saline $(n=10)$ versus $4.49 \pm 0.34 \mathrm{~g}$ MIA $(n=10)$. Both groups of animals lost weight in the first $24 \mathrm{~h}$ after HI: $-0.39 \pm 0.24 \mathrm{~g}$ versus $-0.34 \pm 0.21 \mathrm{~g}$; after this, the weight then plateaued. There was no significant difference in weight loss between the two groups during the 48-h period (analysis of variance [ANOVA]).

The separate regions of the forebrain (cortex, hippocampus, striatum, and thalamus) showed different sensitivity in their response to the carotid occlusion and $1 \mathrm{~h}$ hypoxia $\left(F_{3,21}=\right.$ $47.7, p<0.05$, ANOVA). The effects were particularly severe in the hippocampus and much milder in the cortex, striatum, and thalamus. No change was observed in the hypothalamus or brainstem. There was no significant difference between litters in their response to the HI.

Pretreatment with MIA resulted in an increase in surviving brain tissue, from $44 \%$ to $67 \%(p<0.05)$ in the affected forebrain regions, compared with the contralateral side (Fig. 1). Pretreatment with MIA resulted in an increase in surviving brain tissue in the cortex from $50 \%$ to $76 \%(p<$ $0.05)$ and an increase in the hippocampus from $10 \%$ to $19 \%$ $(p<0.05)$. Treatment also resulted in an increase in tissue survival in the thalamus from $56 \%$ to $64 \%$ and an increase in the striatum from $34 \%$ to $47 \%$, but these did not reach statistical significance (Fig. 2). However, ANOVA common factor analysis revealed MIA to have a highly significant overall protective effect against carotid occlusion and $1 \mathrm{~h}$ of $8 \%$ hypoxia across the different brain regions $\left(F_{1,21}=11.2\right.$, $p<0.05)$.

Moderate insult. Twenty animals underwent the moderate insult protocol. Three animals died during the hypoxia (two MIA, one saline). There was no significant difference in weight between the two groups at the onset of treatment with
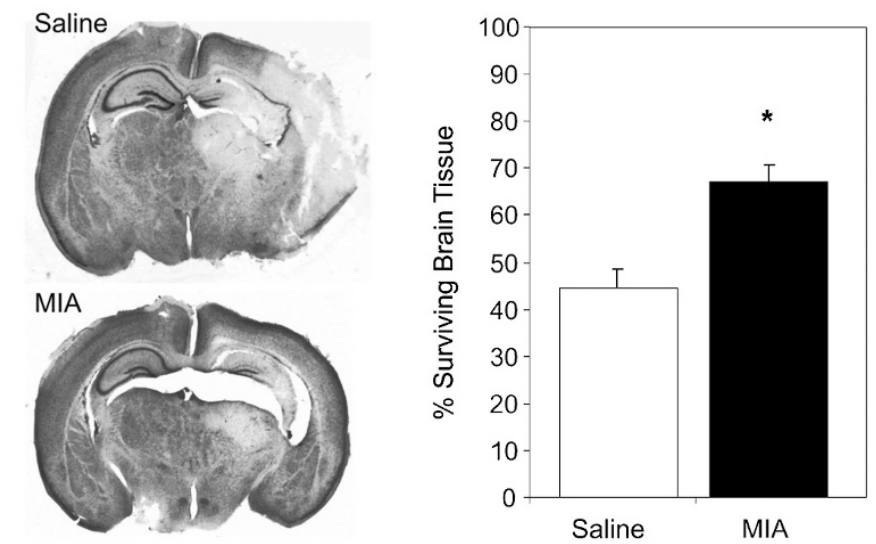

Figure 1. Effects of MIA after severe HI. (A) Cresyl coronal sections $48 \mathrm{~h}$ after carotid occlusion and $1 \mathrm{~h}$ of hypoxia. Note the substantial loss of cortical tissue and the maintenance of the hippocampal dentate gyrus. The ventral cortex, amygdala, and hypothalamus appear unaffected. (B) Pretreatment with MIA resulted in a significant increase in surviving total forebrain hemispheric tissue expressed as the percentage of the unaffected hemisphere: MIA $(n=7)$, saline $(n=5) ;(n=7 / 5) . * p<0.05$ (Student $t$ test). 


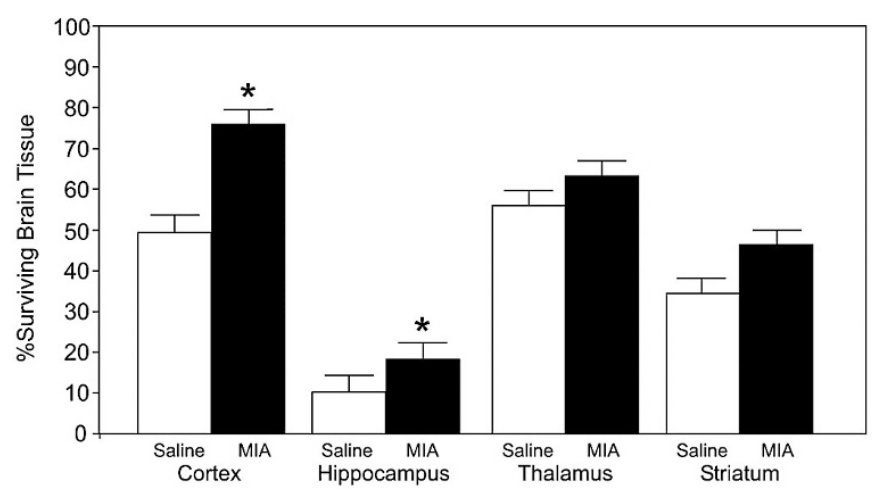

Figure 2. Effects of MIA after severe HI on different forebrain regions. Treatment with MIA resulted in a significant increase in cortical $(p<0.05)$ and hippocampal $(p<0.05)$ tissue expressed as a percentage of unaffected hemisphere but not in the thalamus and striatum $(n=7 / 5)$.

$3.62 \pm 0.71 \mathrm{~g}$ saline $(n=10)$ versus $3.77 \pm 0.74 \mathrm{~g}$ MIA $(n=10)$. Both groups of animals continued to gain weight over the $48 \mathrm{~h}$ after $\mathrm{HI}$, and there was no significant difference in weight gain between the two groups at $48 \mathrm{~h}(0.35 \pm 0.54 \mathrm{~g}$ versus $0.27 \pm 0.46 \mathrm{~g}$ ).

Histologic damage was only observed in the hippocampus with loss of neurons predominantly within CA1 and CA2. There was a relative preservation of neurons within the dentate gyrus. Immunohistochemistry for $\alpha \mathrm{M} \beta 2$ integrin demonstrated both macrophage activation and the presence of deramified phagocytes in the same regions as histologic damage (Fig. 3).

Pretreatment with MIA resulted in a reduction in the mean injury score in the hippocampus, from $3.1 \pm 1.8$ to $0.7 \pm 1.1$ $(p<0.05)$ and a reduction in the average injury score across all affected forebrain regions from $1.0 \pm 0.6$ to $0.2 \pm 0.3$ $(p<0.05)$. Treatment also resulted in reduced injury scores in the cortex, thalamus, and striatum, but these did not reach statistical significance (Fig. 4).

After the moderate insult, TUNEL staining only showed significant DNA fragmentation in CA1 and CA2 of the hippocampus in the injured hemisphere. Occasional TUNELpositive cells were seen in other regions such as the dentate gyrus and cerebral cortex; however, no difference was ob-

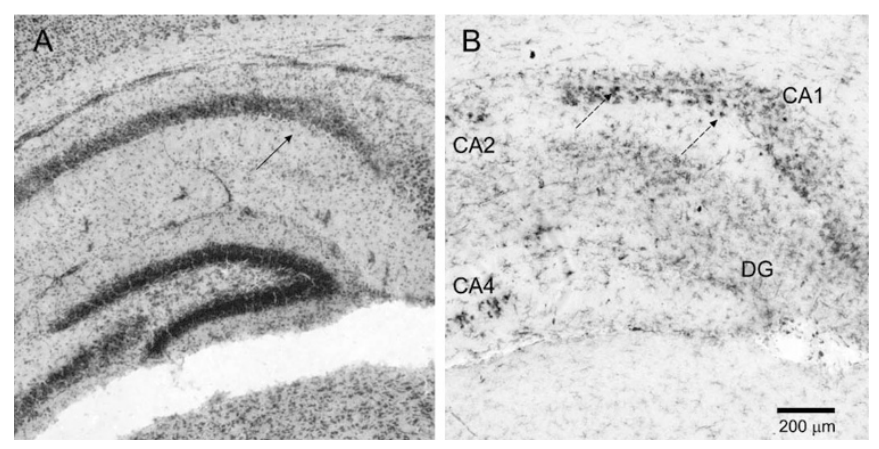

Figure 3. Sequential coronal sections stained with Nissl $(A)$ and immunohistochemistry for $\alpha \mathrm{M} \beta 2$ integrin $(B)$ in the hippocampus after carotid occlusion and 30 min of hypoxia. Mild neuronal loss is seen in CA1 (arrow), immunohistochemistry reveals macrophage activation and presence of deramified phagocytes (dashed arrows). Note the activation in CA1 and CA4 with maintenance of CA2 and dentate gyrus (DG).

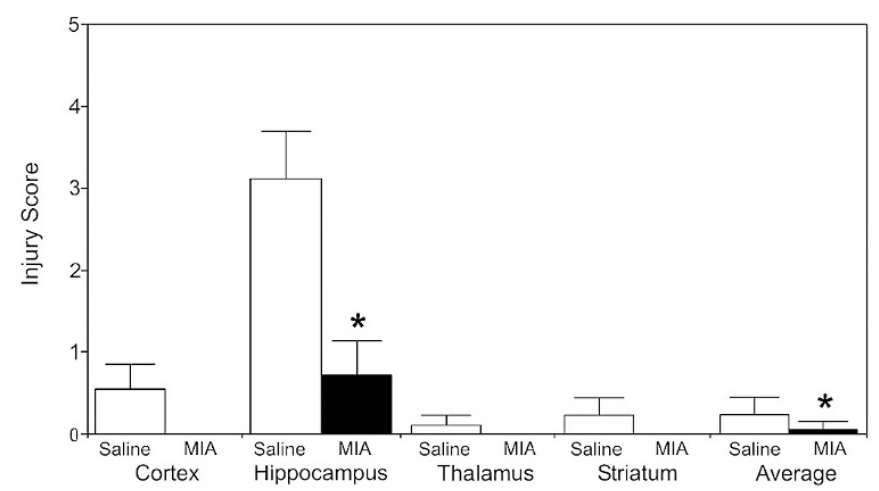

Figure 4. Effects of MIA after moderate HI on different forebrain regions. Treatment with MIA $(2.5 \mathrm{mg} / \mathrm{kg})$ resulted in a significant decrease in average injury score $(p<0.05)$ and in the hippocampus $(p<0.05)$. A neuroprotective trend was seen in the cortex thalamus and striatum $n=9 / 7$ (Student $t$ test).

served between the injured and contralateral hemisphere or between treatment groups in other brain regions. Pretreatment with MIA resulted in a reduction in the average number of TUNEL-positive within the hippocampus, from $241 \pm 262$ cells $/ \mathrm{mm}^{2}$ to $21 \pm 55$ cells $/ \mathrm{mm}^{2}(p<0.05)$ (Fig. 5).

\section{DISCUSSION}

Treatment with MIA started before HI ameliorated histologic brain injury at $48 \mathrm{~h}$ after $\mathrm{HI}$ in a neonatal mouse model. Importantly in this model, neuroprotection was seen after HI of varying severity. The results from this study are consistent with the increasing evidence that NHE blockade may be beneficial to cell survival after HI. Blockade of the NHE has previously been shown to confer neuroprotection in adult rats when administered immediately after focal cerebral ischemia (24). In a tissue culture model of cerebral ischemia, the prevention of rebound alkalosis using amiloride after in vitro HI delayed the onset of injury for as long as the cells remained acidotic (25). Recent studies in an ex vivo model of neonatal rat brain slices demonstrated a preservation of brain slice energetics over several hours in those brain slices exposed to amiloride; this preservation of brain slice energetics with amiloride was similar to that observed in brain slices main-
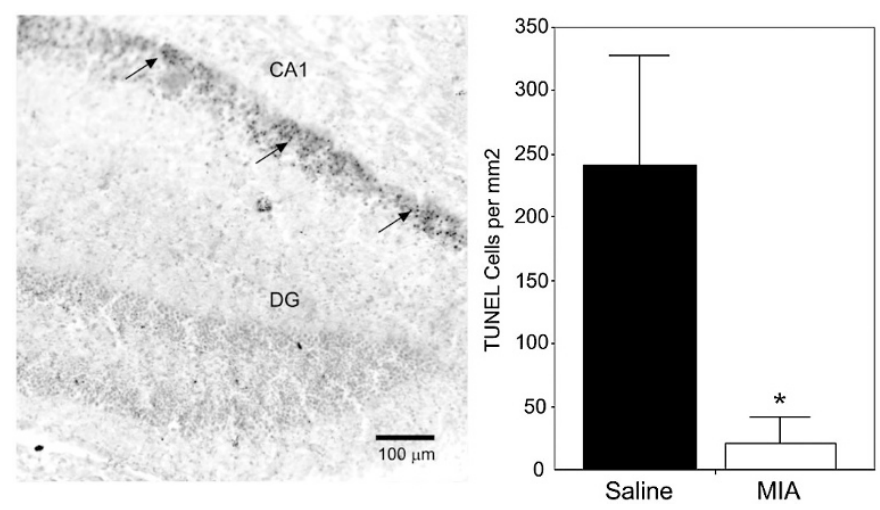

Figure 5. Effects of MIA on TUNEL-positive cells within the hippocampus. (A) TUNEL-stained cells in the CA1 of the hippocampus (arrows); note occasional TUNEL-positive cells within the dentate gyrus (DG). (B) Pretreatment with MIA results in a significant reduction in TUNEL-positive cells, $n$ $=9 / 7,{ }^{*} p<0.05$ (Student $t$ test). 
tained under hypothermic conditions (26). Further in vivo studies in neonatal models are required to demonstrate whether amiloride retains its neuroprotective effect when treatment is commenced after $\mathrm{HI}$ and whether its neuroprotective effect is enhanced in combination with other strategies such as hypothermia.

In this study, the dose of $2.5 \mathrm{mg} / \mathrm{kg}$ MIA was selected as a similar dose in adult rats has been shown to cross the bloodbrain barrier and to be a potent inhibitor of the NHE (20). The absence of enhanced weight loss in MIA-treated animals suggests that, at this dose, the drug is nontoxic and well tolerated. As amiloride is currently used on occasion in the clinical setting as a potassium-sparing diuretic and is not teratogenic or toxic, it may be possible in the future to use amiloride analogues clinically, especially if they retain their neuroprotective effects when given after HI. However, as amiloride crosses the placenta, it also may be possible to administer it to high-risk mothers before delivery to provide protection from brain injury during reperfusion.

One of the mechanisms by which amiloride is neuroprotective may be by preventing rebound brain intracellular alkalosis through blockade of the NHE. Mild acidosis (both extra- and intracellular) during reperfusion after transient $\mathrm{HI}$ has previously been shown to protect the brain $(27,28)$. An alkaline brain $\mathrm{pH}_{\mathrm{i}}$ may exacerbate injury during secondary energy failure by various mechanisms: alkaline $\mathrm{pH}_{\mathrm{i}}$ exacerbates excitotoxic neuronal injury due to increased $N$-methyl-Daspartate activation $(29,30)$ and activation of phospholipases and proteases, which have an alkaline pKa (31). Inhibition of the NHE has been shown to block phospholipase activation in the ischemic/reperfused rat cerebral cortex as a consequence of its stabilizing effect on acidotic $\mathrm{pH}_{\mathrm{i}}$ and preventing alkalosis (32). Changes in $\mathrm{pH}_{\mathrm{i}}$ result in alterations of the delicate balance of pro- and antiapoptotic triggers in mitochondria. Alkalinization has been shown to (i) activate Bax (a proapoptotic protein), inducing its mitochondrial translocation (33); (ii) inhibit the import of adenosine diphosphate into mitochondria, which impairs the synthesis of adenosine triphosphate (34), and (iii) transform the mitochondrial permeability transition pore into a high conductance state, a critical step leading to cell commitment to death (35).

Further mechanisms of neuroprotection by amiloride may relate to a reduction in energy consumption and calcium influx into the cell. As well as influencing $\mathrm{pH}_{\mathrm{i}}$, the excessive action of the NHE after HI leads to an increase in intracellular $\mathrm{Na}^{+}$ concentration and subsequent activation of the $\mathrm{Na}^{+} / \mathrm{K}^{+}$ ATPase, consuming cellular energy. The high intracellular $\mathrm{Na}^{+}$level also activates the sarcolemmal $\mathrm{Na}^{+} / \mathrm{Ca}^{2+}$ antiporter leading to an increase in intracellular $\mathrm{Ca}^{2+}(10,36)$. This calcium overload leads to a variety of deleterious effects including mitochondrial accumulation of calcium, activation of proteolytic enzymes, free radical production, and lipolysis.

In addition to these direct effects on neuronal $\mathrm{pH}_{\mathrm{i}}$ and ion transport, it is also possible that the neuroprotective effects of amiloride may be mediated through interaction with other cell types, including blood vessel endothelia, astrocytes, and neutrophil granulocytes. An amelioration of endothelial cell dysfunction after transient ischemia has been observed with NHE inhibition (37). NHE inhibition was also associated with reduced blood-brain barrier disruption, improved postischemic perfusion, and neuroprotection (37). In astrocyte cultures, oxygen and glucose deprivation resulted in a large increase in intracellular sodium and an increase in cell volume (10). NHE inhibition or genetic ablation of NHE1 reduced the increase in intracellular sodium and astrocyte swelling (38). Finally, NHE inhibition influences neutrophil granulocytes, which are known to invade central nervous system tissue after direct trauma or ischemia (39). Neutrophil chemotaxis is associated with cytoplasmic alkalinization; such chemotactic behavior is inhibited by NHE disruption or amiloride $(40,41)$. Following phagocytosis, neutrophils undergo an NHEmediated rebound alkalosis that is associated with an increase in the generation of superoxide radicals $(41,42)$. The precise neutrophil $\mathrm{pH}_{\mathrm{i}}$ after phagocytosis is believed to play a pivotal role in the regulation of neutrophil apoptosis (43). The role of neutrophils in the generation of brain injury is further emphasized by a study of neonatal rats that were rendered neutropenic with an antineutrophil serum and that displayed a $70 \%$ reduction in brain swelling after HI injury (39). Interestingly, our preliminary data show an $80 \%$ reduction in the neutrophil count in the amiloride-treated animals (Kendall and Raivich, unpublished). It is still unclear, however, whether this is the direct effect of amiloride or secondary to brain injury amelioration. Nevertheless, all three cell types, endothelia, astrocytes, and the newly recruited blood-borne neutrophil granulocytes, may provide additional nonneuronal targets for a neuroprotective action of NHE inhibitor drugs such as amiloride.

Our findings support the increasing in vitro, ex vivo, and in vivo evidence that NHE blockade with resultant delay in the rapid return of $\mathrm{pH}_{\mathrm{i}}$ and prevention of rebound alkalosis may be beneficial to cell survival after $\mathrm{HI}$ and may therefore represent a potential useful therapeutic intervention in the future. Further in vivo studies in neonatal models are required to demonstrate whether amiloride retains its neuroprotective effect when treatment is commenced after HI and whether its neuroprotective effect is enhanced in combination with other strategies such as hypothermia.

\section{REFERENCES}

1. Levene M, Evans DJ 2005 Hypoxic-ischaemic brain injury. In: Rennie JM (ed) Roberton's Textbook of Neonatology. Elsevier/Churchill Livingstone, Philadelphia, pp 1128-1148.

2. Hope PL, Costello AM, Cady EB, Delpy DT, Tofts PS, Chu A, Hamilton PA, Reynolds EO, Wilkie DR 1984 Cerebral energy metabolism studied with phosphorous NMR spectroscopy in normal and birth-asphyxiated infants. Lancet 2:366-370

3. Younkin DP, Delivoria-Papadopoulos M, Leonard JC, Subramanian VH, Eleff S, Leigh Jr,JS Chance B 1984 Unique aspects of human newborn cerebral metabolism evaluated with phosphorus nuclear magnetic resonance spectroscopy. Ann Neurol 16:581-586

4. Laptook AR, Corbett RJ, Uauy R, Mize C, Mendelsohn D, Nunnally RL 1989 Use of 31P magnetic resonance spectroscopy to characterize evolving brain damage after perinatal asphyxia. Neurology 39:709-712

5. Lorek A, Takei Y, Cady EB, Wyatt JS, Penrice J, Edwards AD, Peebles D, Wylezinska M, Owen-Reece H, Kirkbride V, et al 1994 Delayed ('secondary') cerebral energy failure following acute hypoxia-ischaemia in the newborn piglet: continuous 48 -hour studies by $31 \mathrm{P}$ magnetic resonance spectroscopy. Pediatr Res 36:699-706

6. Penrice J, Lorek A, Cady EB, Amess PN, Wylezinska M, Cooper CE, D'Souza P, Brown GC, Kirkbride V, Edwards AD, Wyatt JS, Reynolds EO 1997 Proton magnetic resonance spectroscopy of the brain during acute hypoxia-ischemia and delayed cerebral energy failure in the newborn piglet. Pediatr Res 41:795-802 
7. Gluckman PD, Wyatt JS, Azzopardi D, Ballard R, Edwards AD, Ferriero DM, Polin RA, Robertson CM, Thoresen M, Whitelaw A, Gunn AJ 2005 Selective head cooling with mild systemic hypothermia after neonatal encephalopathy: multicentre randomised trial. Lancet 365:663-670

8. Shankaran S, Laptook AR, Ehrenkranz RA, Tyson JE, McDonald SA, Donovan EF, Fanaroff AA, Poole WK, Wright LL, Higgins RD, Finer NN, Carlo WA, Duara S, Oh W, Cotten CM, Stevenson DK, Stoll BJ, Lemons JA, Guillet R, Jobe AH 2005 National Institute of Child Health and Human Development Neonatal Research Network. Whole-body hypothermia for neonates with hypoxic-ischemic encephalopathy. N Engl J Med 13;353:1574-1584

9. Eicher DJ, Wagner CL, Katikaneni LP, Hulsey TC, Bass WT, Kaufman DA, Horgan MJ, Languani S, Bhatia JJ, Givelichian LM, Sankaran K, Yager JY 2005 Moderate hypothermia in neonatal encephalopathy: safety outcomes. Pediatr Neurol 32:18-24

10. Masereel B, Pochet L, Laeckmann D 2003 An overview of inhibitors of $\mathrm{Na}(+) / \mathrm{H}(+)$ exchanger. Eur J Med Chem 38:547-554

11. Azzopardi D, Wyatt JS, Cady EB, Delpy DT, Baudin J, Stewart AL, Hope PL, Hamilton PA, Reynolds EO 1989 Prognosis of newborn infants with hypoxicischemic brain injury assessed by phosphorus magnetic resonance spectroscopy. Pediatr Res 25:445-451

12. Wakabayashi S, Fafournoux P, Sardet C, Pouyssegur J 1992 The $\mathrm{Na}+/ \mathrm{H}+$ antiporter cytoplasmic domain mediates growth factor signals and controls " $\mathrm{H}(+)$-sensing." Proc Natl Acad Sci U S A 89:2424-2428

13. Mabe H, Blomqvist P, Siesjo BK 1983 Intracellular $\mathrm{pH}$ in the brain following transient ischemia. J Cereb Blood Flow Metab 31:109-114

14. Chopp M, Chen H, Vande Linde AM, Brown E, Welch KM 1990 Time course of postischemic intracellular alkalosis reflects the duration of ischemia. J Cereb Blood Flow Metab 10:860-865

15. Hugg JW, Duijn JH, Matson GB, Maudsley AA, Tsuruda JS, Gelinas DF, Weiner MW 1992 Elevated lactate and alkalosis in chronic human brain infarction observed by $1 \mathrm{H}$ and 31P MR spectroscopic imaging. J Cereb Blood Flow Metab 12:734-744

16. Levine SR, Helpern JA, Welch KM, Vande Linde AM, Sawaya KL, Brown EE, Ramadan NM, Deveshwar RK, Ordidge RJ 1992 Human focal cerebral ischemia: evaluation of brain $\mathrm{pH}$ and energy metabolism with P-31 NMR spectroscopy. Radiology 185:537-544

17. Welch KM, Levine SR, Helpern JA 1990 Pathophysiological correlates of cerebral ischemia the significance of cellular acid base shifts. Funct Neurol 5:21-31

18. Robertson NJ, Cowan FM, Cox IJ, Edwards AD 2002 Brain alkaline intracellular pH after neonatal encephalopathy. Ann Neurol 52:732-742

19. Robertson NJ, Cox IJ, Cowan FM, Counsell SJ, Azzopardi D, Edwards AD 1999 Cerebral intracellular lactic alkalosis persisting months after neonatal encephalopathy measured by magnetic resonance spectroscopy. Pediatr Res 46:287-296

20. Ferimer HN, Kutina KL, LaManna JC 1995 Methyl isobutyl amiloride delays normalization of brain intracellular $\mathrm{pH}$ after cardiac arrest in rats. Crit Care Med 23:1106-1111

21. Moller JC, Klein MA, Haas S, Jones LL, Kreutzberg GW, Raivich G 1996 Regulation of thrombospondin in the regenerating mouse facial motor nucleus. Glia 17:121-132

22. Gavrieli Y, Sherman Y, Ben-Sasson SA 1992 Identification of programmed cell death in situ via specific labeling of nuclear DNA fragmentation. J Cell Biol 119:493-501

23. Ohno M, Aotani H, Shimada M 1995 Glial responses to hypoxic/ischemic encephalopathy in neonatal rat cerebrum. Brain Res Dev Brain Res 84:294-298

24. Horikawa N, Nishioka M, Itoh N, Kuribayashi Y, Matsui K, Ohashi N 2001 The $\mathrm{Na}(+) / \mathrm{H}(+)$ exchanger SM-20220 attenuates ischemic injury in in vitro and in vivo models. Pharmacology 63:76-8
25. Vornov JJ, Thomas AG, Jo D 1996 Protective effects of extracellular acidosis and blockade of sodium/hydrogen ion exchange during recovery from metabolic inhibition in neuronal tissue culture. J Neurochem 67:2379-2389

26. Robertson NJ, Bhakoo K, Puri BK, Edwards AD, Cox IJ 2005 Hypothermia and amiloride preserve energetics in a neonatal brain slice model. Pediatr Res 58:288 296

27. Simon RP, Niro M, Gwinn R 1993 Brain acidosis induced by hypercarbic ventilation attenuates focal ischemic injury. J Pharmacol Exp Ther 267:1428-1431

28. Vannucci RC, Towfighi J, Brucklacher RM, Vannucci SJ 2001 Effect of extreme hypercapnia on hypoxic-ischemic brain damage in the immature rat. Pediatr Res 49:799-803

29. Traynelis SF, Cull-Candy SG 1990 Proton inhibition of N-methyl-D-aspartate receptors in cerebellar neurons. Nature 345:347-350

30. Giffard RG, Weiss JH, Choi DW 1992 Extracellular alkalinity exacerbates injury of cultured cortical neurons. Stroke 23:1817-1821

31. Mellgren RL 1987 Calcium-dependent proteases: an enzyme system active at cellular membranes? FASEB J 1:110-115

32. Phillis JW, Ren J, O'Regan MH 2000 Inhibition of $\mathrm{Na}(+) / \mathrm{H}(+)$ exchange by 5-(N-ethyl-N-isopropyl)-amiloride reduces free fatty acid efflux from the ischemic reperfused rat cerebral cortex. Brain Res 884:155-162

33. Khaled AR, Kim K, Hofmeister R, Muegge K, Durum SK 1999 Withdrawal of IL-7 induces Bax translocation from cytosol to mitochondria through a rise in intracellular $\mathrm{pH}_{\mathrm{i}}$. Proc Natl Acad Sci U S A 96:14476-14481

34. Khaled AR, Reynolds DA, Young HA, Thompson CB, Muegge K, Durum SK 2001 Interleukin-3 withdrawal induces an early increase in mitochondrial membrane potential unrelated to the Bcl-2 family. Roles of intracellular $\mathrm{pH}$, ADP transport and $\mathrm{F}\left({ }_{\mathrm{O}}\right) \mathrm{F}\left({ }_{1}\right)$-ATPase. J Biol Chem 276:6453-6462

35. Lemasters JJ, Nieminen AL, Qian T, Trost LC, Herman B 1997 The mitochondrial permeability transition in toxic, hypoxic and reperfusion injury. Mol Cell Biochem 174:159-165

36. Manev H, Bertolino M, DeErausquin G 1990 Amiloride blocks glutamate-operated cationic channels and protects neurons in culture from glutamate-induced death. Neuropharmacology 29:1103-1110

37. Horikawa N, Kuribayashi Y, Itoh N, Nishioka M, Matsui K, Kawamura N, Ohashi $\mathrm{N} 2001 \mathrm{Na}+/ \mathrm{H}+$ exchange inhibitor SM-20220 improves endothelial dysfunction induced by ischemia-reperfusion. Jpn J Pharmacol 85:271-277

38. Kintner DB, Su G, Lenart B, Ballard AJ, Meyer JW, Ng LL, Shull GE, Sun D 2004 Increased tolerance to oxygen and glucose deprivation in astrocytes from $\mathrm{Na}(+) /$ $\mathrm{H}(+)$ exchanger isoform 1 null mice. Am J Physiol Cell Physiol 287:C12-C21

39. Hudome S, Palmer C, Roberts RL, Mauger D, Housman C, Towfighi J 1997 The role of neutrophils in the production of hypoxic-ischemic brain injury in the neonatal rat. Pediatr Res 41:607-616

40. Simchowitz L, Cragoe EJ Jr 1986 Regulation of human neutrophil chemotaxis by intracellular pH. J Biol Chem 261:6492-6500.

41. Fukushima T, Waddell TK, Grinstein S, Goss GG, Orlowski J, Downey GP 1996 $\mathrm{Na}+/ \mathrm{H}+$ exchange activity during phagocytosis in human neutrophils: role of $\mathrm{FC}$ gamma receptors and tyrosine kinases. J Cell Biol 132:1037-1052

42. Simchowitz L 1985 Intracellular $\mathrm{pH}$ modulates the generation of superoxide radicals by human neutrophils. J Clin Invest 76:1079-1089

43. Coakley RJ, Taggart C, McElvaney NG, O’Neill SJ 2002 Cytosolic pH and the inflammatory microenvironment modulate cell death in human neutrophils after phagocytosis. Blood 100:3383-3391 